Mitchell M. Levy

Andrew Rhodes

Gary S. Phillips

Sean R. Townsend

Christa A. Schorr

Richard Beale

Tiffany Osborn

Stanley Lemeshow

Jean-Daniel Chiche

Antonio Artigas

R. Phillip Dellinger

\title{
Surviving Sepsis Campaign: association between performance metrics and outcomes in a 7.5-year study
}

Received: 31 August 2014

Accepted: 12 September 2014

Published online: 1 October 2014

(C) Springer-Verlag Berlin Heidelberg and ESICM 2014

This article is being simultaneously published in Critical Care Medicine and Intensive Care Medicine.

Electronic supplementary material The online version of this article (doi: 10.1007/s00134-014-3496-0) contains supplementary material, which is available to authorized users.

\section{M. Levy (}

Alpert Medical School at Brown University, Rhode Island Hospital, Providence,

RI, USA

e-mail: Mitchell_Levy@brown.edu

\section{A. Rhodes}

St. George's Healthcare NHS Trust and St George's University of London, London, UK

\section{G. S. Phillips}

The Ohio State University Center for Biostatistics, Columbus, OH, USA

\section{S. R. Townsend}

California Pacific Medical Center,

San Francisco, CA, USA

C. A. Schorr - R. P. Dellinger

Cooper Medical School of Rowan

University, Camden, NJ, USA

R. Beale

Guy's and St. Thomas' NHS Foundation

Trust, London, UK
T. Osborn

Washington University School of Medicine, St. Louis, MO, USA

\section{S. Lemeshow}

The Ohio State University College of Public Health, Columbus, OH, USA

\section{J.-D. Chiche}

Hôpital Cochin, Paris, France

\section{A. Artigas \\ Critical Care Center, Sabadell Hospital, Autonomous University of Barcelona, Barcelona, Spain}
Abstract Purpose: To determine the association between compliance with the Surviving Sepsis Campaign (SSC) performance bundles and mor- tality. Design: Compliance with the SSC performance bundles, which are based on the 2004 SSC guidelines, was measured in 29,470 subjects entered into the SSC database from January 1, 2005 through June 30, 2012. Compliance was defined as evidence that all bundle ele- ments were achieved. Setting: Two hundred eighteen community, aca- demic, and tertiary care hospitals in the United States, South America, and Europe. Patients: Patients from the emergency department, medical and surgical wards, and ICU who met diagnosis criteria for severe sepsis and septic shock. Methods: A multifac- eted, collaborative change intervention aimed at facilitating adoption of the SSC resuscitation and management bundles was introduced.

Compliance with the SSC bundles and associated mortality rate was the primary outcome variable.

Results: Overall lower mortality was observed in high $(29.0 \%)$ versus low $(38.6 \%)$ resuscitation bundle compliance sites $(p<0.001)$ and between high (33.4\%) and low (32.3\%) management bundle compliance sites $(p=0.039)$. Hospital mortality rates dropped $0.7 \%$ per site for every 3 months (quarter) of participation $(p<0.001)$. Hospital and intensive care unit length of stay decreased $4 \%$ (95\% CI $1-7 \% ; p=0.012$ ) for every $10 \%$ increase in site compliance with the resuscitation bundle. Conclusions: This analysis demonstrates that increased compliance with sepsis performance bundles was associated with a $25 \%$ relative risk reduction in mortality rate. Every $10 \%$ increase in compliance and additional quarter of participation in the SSC initiative was associated with a significant decrease in the odds ratio for hospital mortality. These results demonstrate that performance metrics can drive change in clinical behavior, improve quality of care, and may decrease mortality in patients with severe sepsis and septic shock.

Keywords Sepsis .

Performance measures .

Knowledge translation . Surviving Sepsis Campaign . Performance improvement 


\section{Introduction}

The Surviving Sepsis Campaign (SSC) was established in 2002 to assess the public's and clinicians' awareness of sepsis, to develop evidence-based guidelines for the management of severe sepsis and septic shock, and to change clinical behavior through the implementation of those guidelines [1-5]. Since then many hospitals, regulators, public health departments, and lay organizations have developed similar initiatives [6,7] to improve outcomes in patients with severe sepsis and septic shock by facilitating their identification and evidence-based management; many have highlighted an improvement in outcome with reduced mortality [7-10]. At the same time, however, the incidence of severe sepsis and septic shock has increased, which raises the question whether the improvements observed have been due to an overall decline in mortality rather than an improved compliance with sepsis performance metrics [11].

In our previously published results in 15,022 patients, no difference was shown in baseline mortality in hospitals that entered throughout the 2-year study period; i.e., in the SSC study hospitals, the mortality rate was not changing over time [12]. Since that report, the continued participation of some hospitals for 4 years, the introduction of the initiative in newly participating hospitals throughout the 7.5-year study period, and the variation in compliance among participating hospitals enabled the analysis of the longitudinal impact of the performance improvement project and the association between sepsis bundle compliance and mortality.

\section{Methods}

Sites and patient selection

The process of participation in the SSC is described elsewhere [12]. Eligible subjects were those having a suspected site of infection, two or more systemic inflammatory response syndrome criteria [13], and one or more organ dysfunction criteria [12]. Clinical characteristics and time of presentation with severe sepsis were collected for longitudinal analysis. Time of presentation was determined through chart review for the diagnosis of severe sepsis and defined in instructions to data collectors on the SSC website and in educational materials. For patients from the emergency department (ED), the time of presentation was defined as the time of triage.

\section{Data collection}

Data were entered into the SSC database locally at individual hospitals into pre-established, unmodifiable fields.
Data stripped of private health information were submitted every 30 days to the secure master server at the Society of Critical Care Medicine (Mount Prospect, IL).

\section{Institutional review board approval}

The global SSC improvement initiative was approved by the Cooper University Hospital Institutional Review Board (IRB) [Camden, NJ] as meeting criteria for exempt status. The US Department of Health and Human Services' Office for Human Research Protections reiterated that quality improvement activities such as the SSC often qualify for IRB exemption and do not require individual informed consent [14]. Because the Cooper IRB approval would not cover sites outside the United States, those sites were asked, by letter from the SSC, to seek local IRB approval according to local rules and regulations.

\section{Analysis set construction}

The study objective was to characterize the results of the first 4 years of participation in the SSC; thus, the analysis includes a maximum of 16 quarters, which occurred over a 7.5 calendar year period. The first 3 months during which a site entered subjects into the database were defined as the first quarter regardless of when those months occurred. Inclusion in the SSC database was limited to sites with at least 20 subjects and at least 3 months of subject enrollment.

Compliance with the SSC sepsis bundles [12] and associated mortality rates were the primary outcome variables in this study. Two additional working variables were created to help characterize the results. The first variable characterized a site as being in either low or high compliance for both the resuscitation and management bundles. Compliance was defined as evidence that all bundle elements were achieved within the indicated time frame (i.e., $6 \mathrm{~h}$ for the resuscitation bundle; $24 \mathrm{~h}$ for the management bundle). For each site, the proportion of patients in compliance with the resuscitation bundle and the proportion of patients in compliance with the management bundle during the last 2 quarters of participation were generated. Site resuscitation compliance was categorized as low if $<15 \%$ (the median of all sites) or high if $\geq 15 \%$. Similarly, site management compliance was categorized as low if $<20 \%$ (the median of all sites) or high if $\geq 20 \%$. This variable was used to descriptively compare sites across compliance status. When running regression analyses, we used either the continuous proportion values at the site level or the dichotomous compliance values at the patient level. The second working variable was site duration, which categorizes years of participation in the SSC as less than 2 years, 2 to $<3$ years, and 3 or more years. This 3 -level variable 
was used to describe the cohort of patients or sites, while continuous duration in quarters was used in the regression analysis. The duration variable was constant for a site, whereas the site quarter of participation variable described the quarter a particular patient entered the study relative to the first quarter of that site's participation in the SSC.

The primary outcome in this study is hospital mortality and the sepsis severity score (SSS) [15] is used as an adjustment variable to balance patient clinical characteristics across groups not used in the development of the score.

\section{Statistical analysis}

Site-level characteristics are presented as frequencies and percentages and are compared across bundle compliance (high vs. low) using Fisher exact test. Patient-level characteristics are also presented as frequencies and percentages and are compared across compliance using Pearson Chi-square test. Continuous patient-level characteristics are presented as medians along with the interquartile range and are compared across compliance using Wilcoxon rank sum test. The odds of hospital mortality or the odds of individual bundle compliance were estimated using a generalized estimating equation (GEE) population-averaged logistic regression model. The study's goal was not to predict hospital mortality, but to identify the role of site quarter on hospital mortality; therefore, we used a risk factor modeling approach to determine which covariates to add to the GEE model. Only covariates that acted either as a confounder or as an effect modifier were included. A confounder was identified when its addition to the model changed the odds ratio (OR) associated with the site quarter by more than $10 \%$ in either direction, without considering statistical significance. A covariate that had a statistically significant interaction $(p \leq 0.05)$ with site quarter was considered to be an effect modifier. This same approach was used when site duration and patient-level compliance (yes vs. no) was the risk factor or when site-level proportion compliance was the risk factor. The hierarchical nature of the SSC data lends itself to GEE population-averaged logistic regression analysis as patients are nested within a particular site. ICU and hospital lengths of stay were natural log transformed to normalize the distribution and stabilize the variance across low and high resuscitation or management compliance and years of SSC participation. Randomeffects linear regression was used to estimate the change in length of stay for a $10 \%$ increase in the proportion compliant with the resuscitation bundle [16]. Ratios of the geometric means were produced when the model results were back transformed to the original units of days of ICU or hospital stay. All analyses were run using Stata 12.1 (Stata Corporation, College Station, TX).

\section{Results}

A total of 29,470 subjects were included in the analysis set that was constructed from subjects entered into the SSC database from January 1, 2005, through June 30, 2012.

\section{Site characteristics}

The majority of sites were from the United States $(49.1 \%)$ as opposed to Europe $(36.2 \%)$ and South America (14.7\%) (Table 1). High compliance was seen in $102(46.8 \%)$ sites for the resuscitation bundle and 103 $(47.2 \%)$ sites for the management bundle. For both bundles, the highest compliance was in the United States. Distribution of site duration percentages across compliance was similar for both bundles. Sites with fewer than 2 years' duration had low compliance for the resuscitation $(67.2 \%)$ and management $(64.3 \%)$ bundles, while the majority of high-compliance sites for the bundles had 2 or more years' duration $(p<0.001$ and $p=0.010$, respectively).

\section{Patient characteristics}

Table 2 illustrates that most subjects were diagnosed in the ED $(55.8 \%)$ and the majority $(68.2 \%)$ were from the United States. There was some tendency for subjects whose sepsis was identified in places other than the ED to be in the resuscitation bundle low-compliance sites compared to high-compliance sites $(p<0.001)$. A greater percentage of the patients from the United States and Europe were in high-compliance sites (13,538 of 20,086 patients [67.4\%] and 3,477 of 6,609 patients [52.6\%], respectively) compared to low-compliance sites $(6,548$ of 20,086 patients [32.6\%] and 3,132 of 6,609 patients [47.4\%], respectively), while a larger percentage of the South American patients were in low-compliance sites $(1,925$ of 2,775 patients [69.5\%]) compared to highcompliance sites ( 846 of 2,775 patients [30.5\%]; overall $p<0.001$ ). Hospital length of stay, ICU length of stay, and length of stay prior to ICU admission were all longer in low- compared with high-performing resuscitation sites (all $p<0.001$ ).

The clinical characteristics across management compliance can be found in Supplementary Table 1. There was some tendency for subjects whose sepsis was identified in places other than the ED to be in the management bundle high-compliance compared to low-compliance sites, whereas a higher percentage of those identified in the ED were in low-compliance sites $(p<0.001)$. A greater percentage of the patients from Europe and South America were in management bundle high-compliance $(3,766$ of 6,609 [57.0\%] and 1,992 of 2,775 [71.8\%], 
Table 1 Site characteristics across low- and high-compliance sites for resuscitation and management bundles

\begin{tabular}{|c|c|c|c|c|c|c|c|}
\hline \multirow[t]{2}{*}{ Characteristic } & \multicolumn{2}{|c|}{$\begin{array}{l}\text { Low resuscitation compliance } \\
n=116(53.2 \%)\end{array}$} & \multicolumn{2}{|c|}{$\begin{array}{l}\text { High resuscitation compliance } \\
n=102(46.8 \%)\end{array}$} & \multicolumn{2}{|c|}{$\begin{array}{l}\text { Total } \\
n=218\end{array}$} & \multirow[t]{2}{*}{$P^{\mathrm{a}}$} \\
\hline & $n$ & $\%$ & $n$ & $\%$ & $n$ & $\%$ & \\
\hline \multicolumn{7}{|l|}{ Region } & \multirow[t]{4}{*}{0.012} \\
\hline Europe & 49 & 42.2 & 30 & 29.4 & 79 & 36.2 & \\
\hline United States & 46 & 39.7 & 61 & 59.8 & 107 & 49.1 & \\
\hline South America & 21 & 18.1 & 11 & 10.8 & 32 & 14.7 & \\
\hline \multicolumn{7}{|l|}{ Site duration } & \multirow[t]{5}{*}{$<0.001$} \\
\hline$<2$ years & 78 & 67.2 & 42 & 41.2 & 120 & 55 & \\
\hline 2 to $<3$ years & 19 & 16.4 & 37 & 36.3 & 56 & 25.7 & \\
\hline$\geq 3$ years & 19 & 16.4 & 23 & 22.5 & 42 & 19.3 & \\
\hline ICU beds, median (IQR) & 18 & $12-30$ & 16 & $12-27$ & 17.5 & $12-28$ & \\
\hline \multirow[t]{2}{*}{ Characteristic } & \multicolumn{2}{|c|}{$\begin{array}{l}\text { Low management compliance } \\
n=115(52.8 \%)\end{array}$} & \multicolumn{2}{|c|}{$\begin{array}{l}\text { High management compliance } \\
n=103(47.2 \%)\end{array}$} & \multicolumn{2}{|c|}{$\begin{array}{l}\text { Total } \\
n=218\end{array}$} & \multirow[t]{2}{*}{$p^{\mathrm{a}}$} \\
\hline & $n$ & $\%$ & $n$ & $\%$ & $n$ & $\%$ & \\
\hline \multicolumn{7}{|l|}{ Region } & \multirow[t]{4}{*}{0.159} \\
\hline Europe & 42 & 36.5 & 37 & 35.9 & 79 & 36.2 & \\
\hline United States & 61 & 53.0 & 46 & 44.7 & 107 & 49.1 & \\
\hline South America & 12 & 10.4 & 20 & 19.4 & 32 & 14.7 & \\
\hline \multicolumn{7}{|l|}{ Site duration } & \multirow[t]{4}{*}{0.010} \\
\hline$<2$ years & 74 & 64.3 & 46 & 44.7 & 120 & 55.0 & \\
\hline 2 to $<3$ years & 23 & 20.0 & 33 & 32.0 & 56 & 25.7 & \\
\hline$\geq 3$ years & 18 & 15.7 & 24 & 23.3 & 42 & 19.3 & \\
\hline IC $\mathrm{C}$ beds, median (IQR) & 17.5 & $12-30$ & 17.5 & $12-27$ & 17.5 & $12-28$ & 0.920 \\
\hline
\end{tabular}

$I Q R$ interquartile range

${ }^{a} p$ values are based on Fisher exact test

respectively) compared to low-compliance sites (2,843 of 6,609 [43.0 \%] and 783 of 2,775 [28.2\%], respectively), while a larger percentage of US patients were in lowcompliance $(10,187$ of 20,086 [50.7\%]) compared to high-compliance sites $(9,899$ of 20,086 [49.3\%]; overall $p<0.001$ ). Adjusted results indicate that ICU and hospital lengths of stay are not significantly associated with management bundle compliance.

Association between bundle compliance and hospital mortality

Overall mortality was lower in resuscitation bundle highcompliance sites $(29.0 \%)$ compared to low-compliance sites $(38.6 \% ; p<0.001)$; mortality differed less dramatically in management bundle high-compliance sites $(32.3 \%)$ and low-compliance sites $(33.8 \% ; p=0.038)$ (Table 3 ). Hospital mortality rate drops $0.7 \%$ per site quarter of participation $(p<0.001)$ while both resuscitation and management bundle compliance increases for the first 2 years of participation, then plateaus for years 2-4 (Fig. 1). However, the proportion compliant with the resuscitation bundle increases with site quarter of participation, and this increase continues with longer participation in the $\operatorname{SSC}(<2$, 2-3, and 3-4 years) (Fig. 2; Supplementary table 2).
Table 4 presents the results of two GEE populationaveraged logistic regression models. The first uses continuous compliance, either resuscitation or management bundle, as a site-level variable and is measured in the last two quarters of a site's SSC participation. The second uses compliance as a patient-level variable and measures whether or not a patient's ICU visit was compliant with all of the resuscitation or all the management bundle. The first model indicates that hospital mortality decreases $4 \%$ (OR $0.96,95 \%$ CI $0.95-0.97 ; p<0.001$ ) for every additional quarter of SSC participation. Hospital mortality drops $5 \%$ (OR $0.95,95 \%$ CI $0.94-0.97 ; p<0.001$ ) for a $10 \%$ increase in the proportion compliant with the resuscitation bundle while the drop is $3 \%$ (OR 0.97, $95 \%$ CI $0.96-0.98 ; p<0.001)$ for a $10 \%$ increase in the proportion compliant with the management bundle. In the second model, hospital mortality decreases $3 \%$ (OR 0.97 , $95 \%$ CI $0.96-0.98 ; p<0.001)$ for every additional quarter of SSC participation. Hospital mortality drops $18 \%$ (OR 0.82, $95 \%$ CI $0.76-0.88 ; p<0.001$ ) for patient-level compliance with all elements of the resuscitation bundle, while the drop is $14 \%$ (OR 0.76, $95 \%$ CI $0.71-0.81 ; p<0.001)$ if patient-level compliance was achieved for all elements of the management bundle. Both models are adjusted for the SSS, duration of participation in the SSC, and calendar time measured in quarters. 
Table 2 Patient clinical characteristics across low- and high-compliance sites for resuscitation bundle

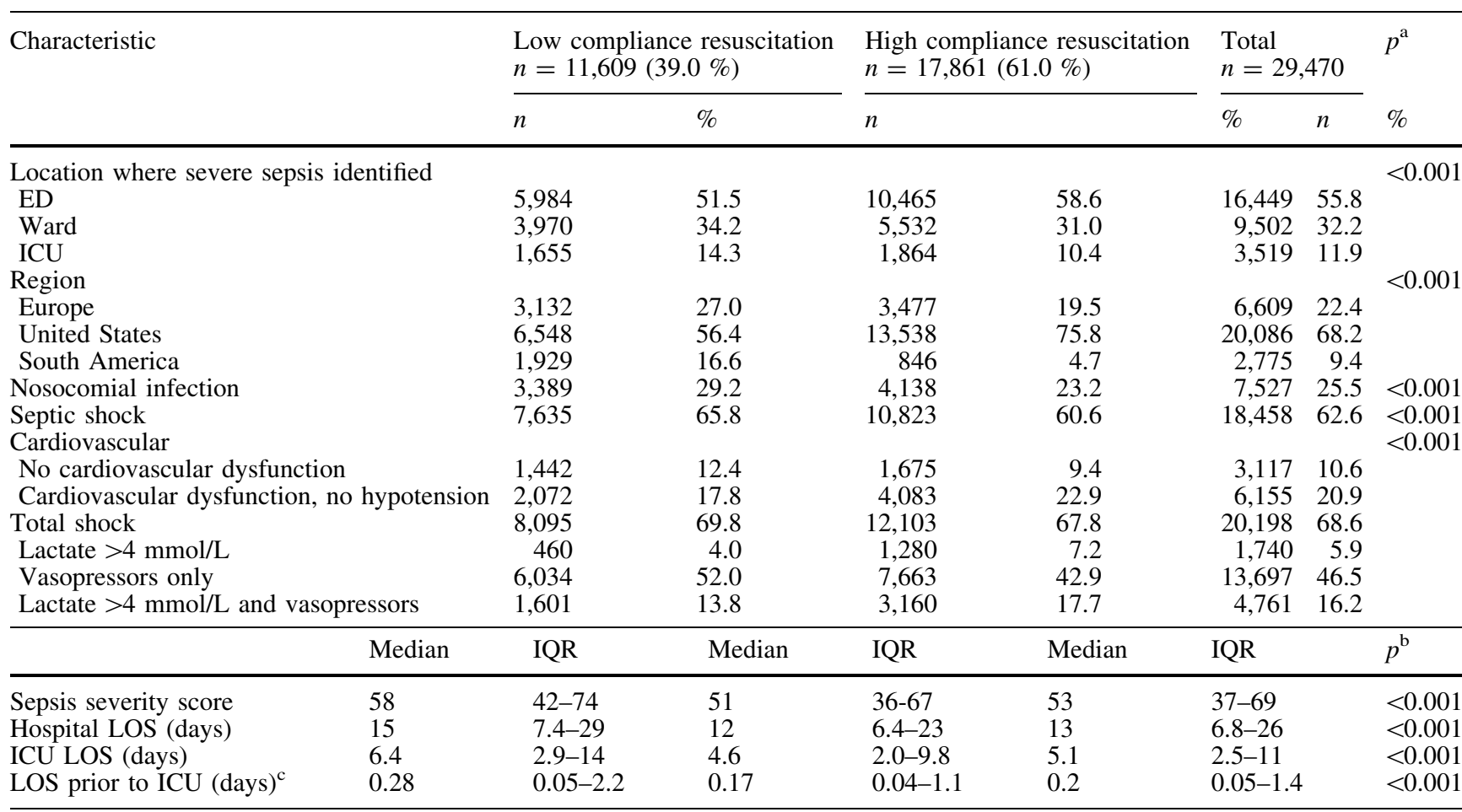

$E D$ emergency department, IQR interquartile range, $L O S$ length of stay

${ }^{a} p$ values are based on Fisher exact test

c If severe sepsis was identified while patient was in the ICU, then

b $p$ values are based on the Wilcoxon rank-sum test

Additionally we tested whether the SSS changed over calendar time using a random-effects linear regression model. The slope coefficient in this model $(\beta=-0.05$, $p=0.609$ ) indicates that the SSS was stable over the period of the study.

Adjusted results indicate that the ICU length of stay decreases $4 \%(95 \%$ CI $1-7 \% ; p=0.012)$ for a $10 \%$ increase in the proportion compliant with the resuscitation bundle. Hospital length of stay also decreases $4 \%(95 \%$ CI $1-7 \% ; p=0.031$ ) for a $10 \%$ increase in the proportion compliant with the resuscitation bundle. These results are adjusted for the SSS, duration in the SSC, survival status (died in the ICU; survived the ICU, but died in the hospital; and survived to hospital discharge), and calendar time measured in quarters.

We wanted to be sure that any decrease in hospital mortality was associated with the SSC and not with a global decrease in mortality in patients with the same severity of illness, because our results were adjusted by the SSS. Thus, using a GEE population-average logistic regression model and only a site's first quarter of participation in SSC $(n=2,592)$, we regressed mortality on calendar time in quarters, while adjusting for the SSS. The adjusted OR is 0.999 (95\% CI 0.973-1.021; $p=0.805$ ), indicating hospital mortality was stable over the duration of participation. Therefore, initial mortality
LOS is interpreted as prior to sepsis identification

rates in all sites entering participation over the study period was not changing over time. Note that these results were not confounded by any other SSC covariates nor were there any SSC effect modifiers of this relationship.

Table 5 presents the odds of hospital mortality for the individual elements of the resuscitation and management bundles. For some of the elements, the interaction with duration in the SSC was significant, and thus these cases have three odds ratios for these elements. Overall each of the elements is protective of hospital mortality as indicated by the odds ratio $<1$. These results are adjusted for the site quarter of participation, SSS, and duration in SSC participation.

\section{Discussion}

This analysis, over a period of 7.5 years, demonstrates that increased compliance with a global sepsis quality improvement initiative was associated with a $25 \%$ relative risk reduction in mortality. The intervention studied was the introduction of a multifaceted, collaborative change intervention aimed at facilitating adoption of the SSC resuscitation and management bundles. Bundle adoption included identification of physician and nurse 
Table 3 Hospital mortality across low- and high-compliance sites for resuscitation management bundles

\begin{tabular}{|c|c|c|c|c|c|c|c|c|c|c|}
\hline \multirow[t]{2}{*}{ Characteristic } & \multicolumn{3}{|c|}{$\begin{array}{l}\text { Low } \\
\text { compliance }\end{array}$} & \multicolumn{3}{|c|}{$\begin{array}{l}\text { High } \\
\text { compliance }\end{array}$} & \multicolumn{3}{|l|}{ Total } & \multirow[t]{2}{*}{$p^{\mathrm{a}}$} \\
\hline & Total $(n)$ & Died $(n)$ & $\%$ & Total $(n)$ & Died $(n)$ & $\%$ & Total $(n)$ & Died $(n)$ & $\%$ & \\
\hline \multirow{2}{*}{$\begin{array}{l}\text { Overall } \\
\text { Location of severe sepsis identification }\end{array}$} & 11,609 & 4,475 & 38.6 & 17,861 & 5,185 & 29.0 & 29,470 & 9,660 & 32.8 & \multirow{5}{*}{$\begin{array}{l}<0.001 \\
<0.001\end{array}$} \\
\hline & & & & & & & & & & \\
\hline ED & 5,984 & 1,850 & 30.9 & 10,465 & 2,421 & 23.1 & 16,449 & 4,271 & 26.0 & \\
\hline Ward & 3,970 & 1,800 & 45.3 & 5,532 & 2,032 & 36.7 & 9,502 & 3,832 & 40.3 & \\
\hline ICU & 1,655 & 825 & 49.8 & 1,864 & 732 & 39.3 & 3,519 & 1,557 & 44.2 & \\
\hline \multirow{4}{*}{$\begin{array}{l}\text { Site duration } \\
<2 \text { years } \\
2 \text { to }<3 \text { years } \\
\geq 3 \text { years }\end{array}$} & & & & & & & & & & \multirow{4}{*}{$<0.001$} \\
\hline & 4,960 & 1,896 & 38.2 & 3,352 & 992 & 29.6 & 8,312 & 2,888 & 34.7 & \\
\hline & 1,611 & 600 & 37.2 & 6,557 & 1,895 & 28.9 & 8,168 & 2,495 & 30.5 & \\
\hline & 5,038 & 1,979 & 39.3 & 7,952 & 2,298 & 28.9 & 12,990 & 4,277 & 32.9 & \\
\hline \multirow[t]{2}{*}{ Characteristic } & \multicolumn{3}{|c|}{ Low management compliance } & \multicolumn{3}{|c|}{ High management compliance } & e Total & & & \multirow[t]{2}{*}{$p^{\mathrm{a}}$} \\
\hline & Total $(n)$ & Died $(n)$ & $\%$ & Total $(n)$ & Died $(n)$ & $\%$ & Total $(n$ & ) Died $(n)$ & $\%$ & \\
\hline \multirow{5}{*}{$\begin{array}{l}\text { Overall } \\
\text { Location where severe sepsis identified } \\
\text { ED } \\
\text { Ward } \\
\text { ICU }\end{array}$} & 13,813 & 4,611 & 33.8 & 15,657 & 5,049 & 32.3 & 29,470 & 9,660 & 32.8 & \multirow{5}{*}{$\begin{array}{r}0.038 \\
<0.001 \\
2\end{array}$} \\
\hline & & & & & & & & & & \\
\hline & 7,958 & 2,127 & 26.7 & 8,491 & 2,144 & 25.3 & 16,449 & 4,271 & 26.0 & \\
\hline & 4,219 & 1,737 & 41.2 & 5,283 & 2,095 & 39.7 & 9,502 & 3,832 & 40.3 & \\
\hline & 1,636 & 747 & 45.7 & 1,883 & 810 & 43.0 & 3,519 & 1,557 & 44.2 & \\
\hline \multirow{4}{*}{$\begin{array}{l}\text { Site duration } \\
<2 \text { years } \\
2 \text { to }<3 \text { years } \\
\geq 3 \text { years }\end{array}$} & & & & & & & & & & \multirow{4}{*}{$<0.001$} \\
\hline & 5,103 & 1,766 & 34.6 & 3,209 & 1,122 & 35.0 & 8,312 & 2,888 & 34.7 & \\
\hline & 2,524 & 894 & 35.4 & 5,644 & 1,601 & 28.4 & 8,168 & 2,495 & 30.5 & \\
\hline & 6,186 & 1,951 & 31.5 & 6,804 & 2,326 & 34.2 & 12,990 & 4,277 & 32.9 & \\
\hline
\end{tabular}

$E D$ emergency department

${ }^{a} p$ values are based on Pearson Chi square test

champions, introduction of the bundles, education, as well as audit and feedback [12]. Several important messages emerge as a result of this study; these can be viewed as participation, duration, and dose effects. Participation effect is seen in the overall decline in mortality associated with participation in the SSC initiative irrespective of the rate of compliance, suggesting that participation in SSC alone is associated with improved patient outcome. Duration effect is seen in the $7 \%$ decline in the risk of mortality for every additional quarter a site participates in the SSC; therefore, the longer a site participated in the SSC initiative, the better the associated patient outcomes (mortality). Dose effect can be seen in the results of compliance as a continuous variable: for every $10 \%$ increase in compliance at a given site, the risk of hospital mortality decreases 3-5\%; therefore, the more compliant a hospital, the better the associated outcome. In addition, in hospitals identified as high-compliance sites, the associated mortality reduction was significantly greater than in the overall patient population: in high-compliance hospitals that participated at least 3 years, a $36 \%$ relative reduction in mortality was achieved, while hospitals that participated at least 4 years had an associated mortality reduction of $39 \%$. This association is a major finding in the efforts of the SSC to change clinical behavior and improve outcomes. A recent report suggested that sepsis mortality has been decreasing over the past decade [11], and a study from Kaukonen et al. [17] reported a decline in sepsis mortality from 35.0 to $18.4 \%$ in Australia and New Zealand between 2000 and 2012. Combined with the fact that sepsis mortality was not decreasing over time in the hospitals entering the SSC database throughout the 7.5-year study period, these results make a compelling argument that the beneficial impact of high compliance with the sepsis bundles is not solely due to the reported overall decline in mortality but is related to the change in clinical practice [11]. This has significant implications for the mandated sepsis reporting efforts now underway in some states [18].

This is the largest prospective cohort of sepsis patients ever reported. Since the original report from the SSC [12], similar studies have been published from individual hospital networks [19-21] and national programs [22]. All published studies have demonstrated an association between improved compliance with guidelines-based sepsis bundles and survival. The results of this study of nearly 30,000 patients show, as in the previous study, that increased compliance with the sepsis performance bundles was associated with decreased mortality, reinforcing the strength of the consistently reported favorable association between compliance and mortality. Also important is the statistically significant decline in mortality rate associated with continued participation in the initiative. For every additional quarter of participation, an associated decrease of $7 \%$ in hospital mortality from sepsis occurred. Given the widespread adoption of sepsis 
Fig. 1 Resuscitation (a) and management (b) Surviving Sepsis Campaign (SSC) bundle compliance and hospital mortality (c). All panels are based on an unadjusted generalized estimating equation population-averaged logistic regression model where circles represent observed values, lines are based on the regression, and shaded areas are the $95 \%$ CIs
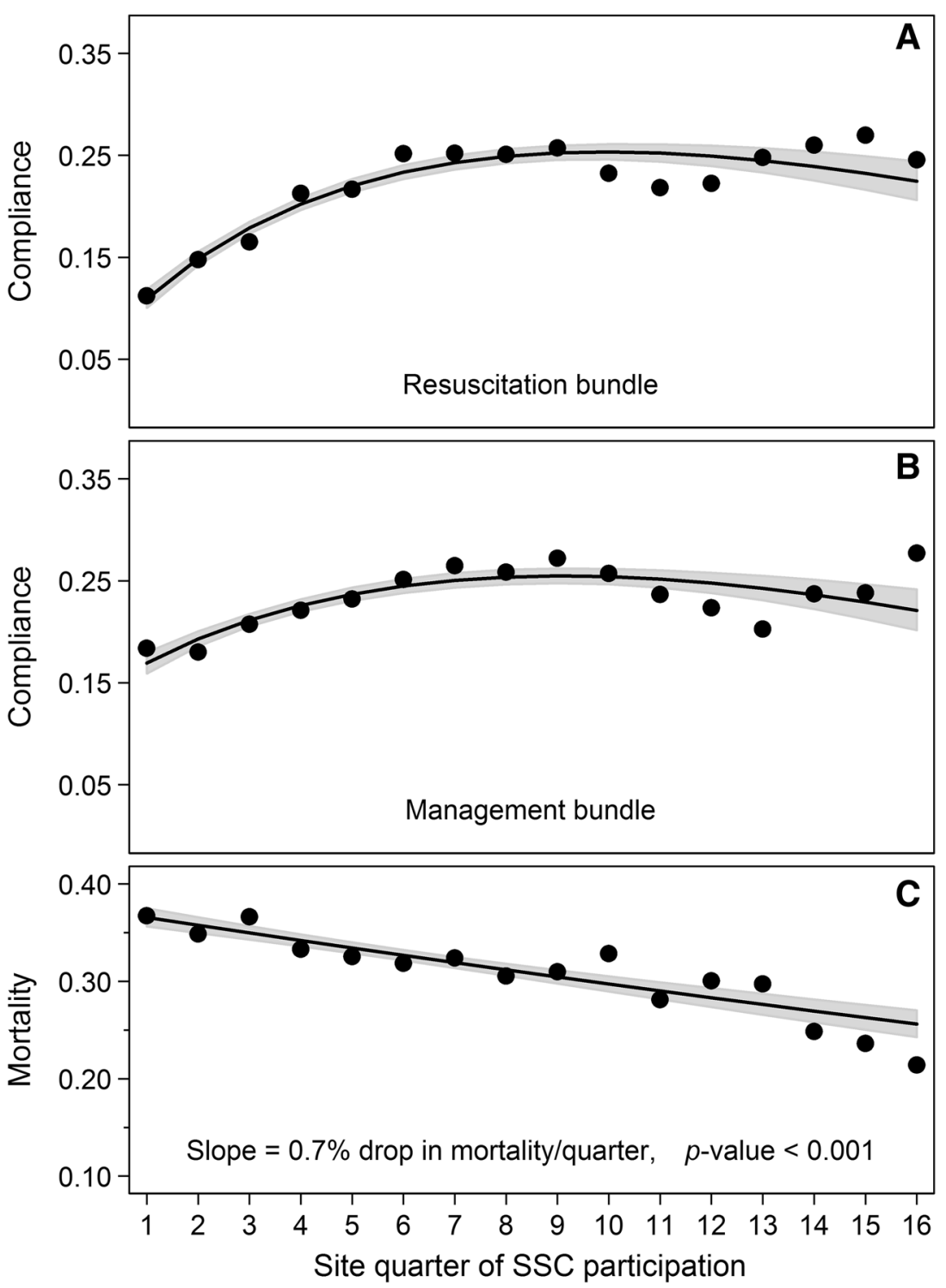

performance improvement initiatives, this is an important message for hospitals and bedside practitioners: the survival benefit associated with performance improvement increases over time. Another important finding is the important beneficial impact on resource utilization: ICU and hospital lengths of stay were significantly lower in high-compliance versus low-compliance hospitals.

This study also points to the difference between observational studies and randomized, controlled trials. In our study, the regression analysis (Table 5) revealed that the bundle elements of central venous pressure (CVP) measurement and central venous oxygen saturation $\left(\mathrm{ScVO}_{2}\right)$ measurement were both independently associated with a decreased odds ratio of mortality. However, the recently published ProCESS study failed to demonstrate any difference in mortality between early goal-directed therapy (CVP and $\mathrm{ScvO}_{2}$ ) or the value of protocolized resuscitation compared with "usual" care [23]. Our study, which is less methodologically robust than a randomized, controlled trial, included these elements in the bundles, along with multiple other elements of care. It is difficult to say which of the elements were most essential to the associated mortality benefit seen with increasing overall bundle compliance.

Our study has several limitations. It was not a randomized, controlled trial, so no direct causation can be claimed for the effect of compliance on mortality. The statistically significant association between duration of participation and higher compliance with decreasing hospital mortality suggests, however, that compliance with performance metrics is at least, in part, responsible for the improved survival. Another limitation is the lack 
Fig. 2 Resuscitation compliance by duration of years of Surviving Sepsis Campaign (SSC) participation $(<2$ years, a 2 to $<3$ years, b 3-4 years c) and hospital mortality (panel $d$ ). All panels are based on an unadjusted generalized estimating equation populationaveraged logistic regression observed values, lines are based on the regression, and shaded areas are the $95 \%$ CIs model where circles represent
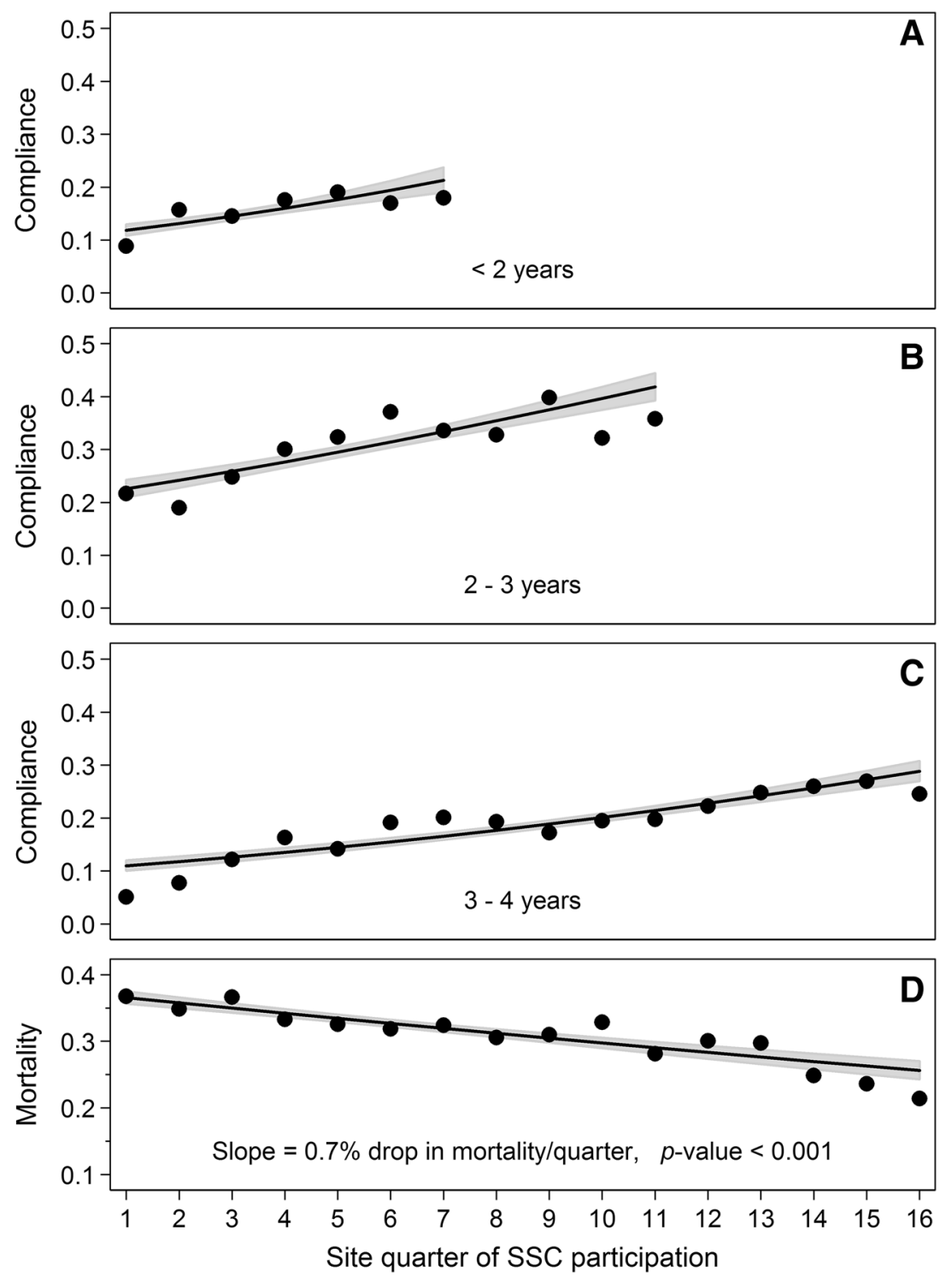

of baseline mortality data. The "baseline" mortality for all sites is mortality after the first quarter of participation in the SSC. The higher-compliance sites demonstrated lower mortality then the low-compliance sites. Rapid declines in associated mortality early in performance improvement initiatives have been reported elsewhere [7, 12]; thus we cannot definitely say if the difference in mortality in low- and high-compliance sites after 3 months in the SSC is due to baseline differences or to highly compliant sites lowering their mortality rates from the beginning. Another limitation is the potential confounding by other hospital quality improvement initiatives on the declining mortality rate seen during participation in the SSC. Other factors, in addition to the SSC sepsis initiative, may have contributed to the decline in hospital mortality. No data were collected on the specific improvement initiatives simultaneously occurring at

all participating institutions. However, results of the analysis with compliance as a continuous variable suggest that there was a significant, positive relationship between duration of participation, increasing compliance, and hospital mortality at each site. The methodology of the performance improvement initiative as a continuous time series does not permit a conclusive determination of causality between bundle compliance and reduced mortality.

Another weakness is the lack of rigorous quality control in data entry. The study spanned three continents and more than 200 hospitals. Data collectors were trained through multiple conference calls and onsite meetings, but no rigorous quality checking of data entry was performed. A further weakness rests in the identification of "time zero." Participants were instructed to establish time zero in the ED at triage time. For the wards and the ICUs, 
Table 4 Odds of hospital mortality for site quarter of participation, resuscitation bundle compliance, and management bundle compliance for two logistic regression models

\begin{tabular}{llll}
\hline Model & Risk factors $^{\text {a }}$ & OR (95\% CI) & $p$ \\
\hline 1. Continuous compliance, either resuscitation or & For every additional quarter of site participation & $0.96(0.95-0.97)$ & $<0.001$ \\
management bundle, as a site-level variable and & $10 \%$ increase in resuscitation compliance & $0.95(0.94-0.97)$ & $<0.001$ \\
measured in last 2 quarters of site's SSC participation & $10 \%$ increase in management compliance & $0.97(0.96-0.98)$ & $<0.001$ \\
\hline 2. Compliance as a patient-level variable and measuring & For every additional quarter of site participation & $0.97(0.96-0.98)$ & $<0.001$ \\
whether patient's ICU visit was compliant with & Resuscitation compliance, yes versus no & $0.82(0.76-0.88)$ & $<0.001$ \\
resuscitation or with management bundle & Management compliance, yes versus no & $0.76(0.71-0.81)$ & $<0.001$ \\
\hline
\end{tabular}

$O R$ odds ratio, SSC Surviving Sepsis Campaign

a Both regression models are based on a generalized estimating equation population-averaged logistic regression and are adjusted for the Sepsis Severity Score, duration in participation in the Surviving Sepsis Campaign, and calendar time measured in quarters.
Note that there was no significant interaction between site quarter of participation and resuscitation bundle compliance, between site quarter of participation and management bundle compliance, and between resuscitation bundle compliance and management bundle compliance

Table 5 Hospital mortality adjusted odds ratio modeled individually for each element in bundle compliance using a generalized estimating equation population-averaged logistic regression

\begin{tabular}{|c|c|c|c|c|}
\hline $\begin{array}{l}\text { Initial care bundle } \\
\text { (First } 6 \mathrm{~h} \text { of presentation) }\end{array}$ & Participation in SSC (years) & Hospital mortality $\mathrm{OR}^{\mathrm{a}}$ & $95 \%$ CI & $p$ \\
\hline \multirow[t]{3}{*}{ Measured lactate } & $<2$ & 0.80 & $0.73-0.89$ & $<0.001$ \\
\hline & 2 to $<3$ & 0.67 & $0.59-0.76$ & $<0.001$ \\
\hline & $>3$ & 0.69 & $0.63-0.75$ & $<0.001$ \\
\hline Blood cultures before antibiotics & $\bar{N}$ at applicable ${ }^{b}$ & 0.82 & $0.77-0.87$ & $<0.001$ \\
\hline Broad-spectrum antibiotics & Not applicable ${ }^{b}$ & 0.85 & $0.81-0.90$ & $<0.001$ \\
\hline \multirow[t]{3}{*}{ Fluids and vasopressors } & $<2$ & 0.86 & $0.73-1.01$ & 0.074 \\
\hline & 2 to $<3$ & 0.63 & $0.48-0.81$ & $<0.001$ \\
\hline & $\geq 3$ & 0.74 & $0.62-0.88$ & 0.001 \\
\hline $\mathrm{CVP}>8 \mathrm{~mm} \mathrm{Hg}$ & Not applicable ${ }^{\mathrm{b}}$ & 0.84 & $0.78-0.91$ & $<0.001$ \\
\hline $\mathrm{ScVO}_{2}>70 \%$ & Not applicable ${ }^{b}$ & 0.83 & $0.76-0.90$ & $<0.001$ \\
\hline All resuscitation measures & Not applicable ${ }^{b}$ & 0.79 & $0.73-0.85$ & $<0.001$ \\
\hline \multicolumn{5}{|c|}{ Management bundle (first $24 \mathrm{~h}$ after presentation) } \\
\hline \multirow[t]{3}{*}{ Steroid policy } & $<2$ & 0.96 & $0.84-1.09$ & 0.527 \\
\hline & 2 to $<3$ & 0.76 & $0.64-0.89$ & 0.001 \\
\hline & $>3$ & 0.88 & $0.79-0.99$ & 0.031 \\
\hline rhAPC policy & Not applicable ${ }^{\mathrm{b}}$ & 0.93 & $0.87-1.00$ & 0.061 \\
\hline Glucose policy & Not applicable ${ }^{\mathrm{b}}$ & 0.71 & $0.68-0.75$ & $<0.001$ \\
\hline Plateau pressure control & Not applicable ${ }^{b}$ & 0.81 & $0.74-0.89$ & $<0.001$ \\
\hline All management measures & Not applicable ${ }^{b}$ & 0.74 & $0.69-0.79$ & $<0.001$ \\
\hline
\end{tabular}

SSC Surviving Sepsis Campaign, OR odds ratio, CVP central venous pressure, $\mathrm{SCVO}_{2}$ central venous oxygen saturation, $r h A P C$ recombinant human activated protein $\mathrm{C}$

a Hospital mortality odds ratio for those patients where the bundle element was achieved compared to when the bundle was not achieved, and the results are adjusted by site quarter of participation and the Sepsis Severity Score

triage time was established through chart review, and the onset of severe sepsis with identified by vital signs and laboratory values. This time zero is less rigorous and therefore less reliable than the time zero established for ED patients. Even at the end of this study, in sites with 3and 4-years' worth of data collection, metrics for compliance with such bundle elements as antibiotics, CVP, and $\mathrm{ScVO}_{2}$ were still $<75 \%$ and, in the case of CVP and $\mathrm{ScvO}_{2},<40 \%$. This may, in part, reflect the use of triage time as time zero because a certain percentage of patients developed severe sepsis and septic shock several hours after arriving in the ED. Of interest, a recent multicenter b Not applicable implies there there was not a significant interaction $(p<0.05)$ between the bundle element and years of participation in the Surviving Sepsis Campaign. If the interaction was significant, then the odds ratio is given for each level of participation

trial has called into question the value of CVP and $\mathrm{ScvO}_{2}$ as the sole therapeutic targets in resuscitation of severe sepsis and septic shock [23]. This may certainly impact recommendations for resuscitation and future bundles as additional published data become available.

\section{Conclusion}

The results of the 7.5-year study of the SSC performance improvement initiative demonstrated a greater increase in 
compliance over time in hospitals that continue to participate 2,3 , and up to 4 years. Increasing compliance is associated with a statistically significant decline in mortality rates, and hospital mortality is even lower in hospitals with high versus low bundle compliance. Consistent with the literature, these results lend strength to the argument that performance metrics can be used to drive change in clinical behavior and, therefore, improve the quality of care and lead to decreased mortality in patients with severe sepsis and septic shock.

Acknowledgments The authors gratefully acknowledge Deb McBride for her assistance in the preparation of the manuscript.

Dr. Levy consulted for the Eli Lilly Advisory Board and Baxter Lifesciences. His institution received grant support from Eli Lilly Co. and Baxter Lifesciences (Surviving Sepsis Campaign [SSC] has not received Industry support since 2006). Dr. Rhodes received support for travel from ESICM (supported Dr. Rhodes' work for the SSC), served as an Advisory Board for Astellas, is employed by Eli Lilly (SC member for Prowess Shock trial), and lectured for LiDCO and Edwards Lifesciences. Dr. Phillips' institution received grant support from a National Institutes of Health (NIH) grant and from the Murdoch Children's Research Institution. His institution received support for participation in review activities from Rhode Island Hospital, LifeSpan Partner. Dr. Townsend served as a board member for the Roundtable on Critical Care, consulted for Sutter Health and Dignity Health, is employed by the California Pacific Medical Center, and received grant support from the Betty and Gordon Moore Foundation. Dr. Schorr consulted for the Society of
Critical Care Medicine (SCCM) (Faculty for East and West coast collaboratives). Dr. Beale consulted for Philips Healthcare and received support for travel from the European Society of Intensive Care and the SCCM. His institution served on the board for the Waters Corporation and Nestle Nutrition; he lectured for Nestle Nutrition and Philips Healthcare; and received grant support from Becton Dickinson (Through UK Government Technology Strategy Board Collaborative Grant Programme), Deltex, and Philips Healthcare. Dr. Osborn consulted for the Institute of Healthcare Improvement (sepsis consultant) and received support for travel from the American College of Emergency Physicians (Scientific Assembly 2011, 2012, 2013). Dr. Lemeshows' institution received support for participation in review activities from Rhode Island Hospital, LifeSpan Partner. His institution received grant support from a NIH grant and the Murdoch Children's Research Institution. Dr. Chiche served as board member for GE Healthcare and Nestlé and consulted for Astra Zeneca and Orion Pharma. Dr. Artigas served as board member for Ferrer Pharma; consulted for Almirall, Braun, Hill Rom, and Rubió; and lectured for Phillips, Grifols, Astute, and Hill Rom. His institution received grant support from Grifols. Dr. Dellinger received an honorarium through the SCCM for some of the regional collaborative programs and received support for travel (expenses for regional collaborative programs).

Initial funding for the Surviving Sepsis Campaign (2002-2006) was through unrestricted educational grants from Eli Lilly Co., Edwards Lifesciences, Phillips Medical Systems, and the Coalition for Critical Care Excellence (formed by the SCCM). The sponsors had no involvement in the development, data analysis, or manuscript preparation of this study. No additional funding has been received since that time or during the analysis and development of the study and manuscript.

\section{References}

1. Townsend SR, Schorr C, Levy MM et al (2008) Reducing mortality in severe sepsis: the Surviving Sepsis Campaign. Clin Chest Med 29(4):721-733

2. Levy MM, Pronovost PJ, Dellinger RP et al (2004) Sepsis change bundles: converting guidelines into meaningful change in behavior and clinical outcome. Crit Care Med 32(22 suppl):S595-S597

3. Dellinger RP, Carlet JM, Masur $\mathrm{H}$ et al (2004) For the Surviving Sepsis Campaign Management Guidelines Committee. Surviving Sepsis Campaign guidelines for management of severe sepsis and septic shock. Crit Care Med 32(3):858-873

4. Dellinger RP, Levy MM, Carlet JM et al (2008) For the International Surviving Sepsis Campaign Guidelines Committee Surviving Sepsis Campaign: international guidelines for management of severe sepsis and septic shock. Intensive Care Med 34(1):17-60

5. Dellinger RP, Levy MM, Rhodes A et al (2013) Surviving sepsis campaign: international Guidelines for management of severe sepsis and septic shock. 2012. Intensiv Care Med 39(2):165-228
6. https://www.health.ny.gov/regulations/ public health law/section/405/ (last Accessed 30 September, 2014)

7. New York State Department of Health. Sepsis regulations: guidance document 405.4 (a)(4)

http://www.gnyhafoundation.org/160/ Default.aspx. Last accessed February 28, 2014

8. Angus DC, Linde-Zwirble WT, Lidicker J et al (2001) Epidemiology of severe sepsis in the United States: analysis of incidence, outcome, and associated costs of care. Crit Care Med 29:1303-1310

9. Gaieski DF, Edwards M, Kallan MJ et al (2013) Benchmarking the incidence and mortality of severe sepsis in the Unites States. Crit Care Med 41:1167-1174

10. Dombrovskiy V, Martin AA, Sunderram J et al (2007) Rapid increase in hospitalization and mortality rates for severe sepsis in the United States: a trend analysis from 1993-2003. Crit Care Med 35:1244-1250

11. Stevenson EK, Rubenstein AR, Radin GT et al (2014) Two decades of mortality trends among patients with severe sepsis: a comparative metaanalysis. Crit Care Med 42(3):2-7
12. Levy MM, Dellinger RP, Townsend SR et al (2010) The Surviving Sepsis Campaign: results of an international guideline-based performance improvement program targeting severe sepsis. Intensiv Care Med 36(2):222-231

13. Levy MM, Fink MP, Marshall JC et al (2003) 2001 SCCM/ESICM/ACCP/ ATS/SIS international sepsis definitions conference. Crit Care Med 31(4):1250-1256

14. U.S. Department of Health and Human Services. Human research protections: Quality improvement activities-FAQs. www.hhs.gov/ohrp/qualityfaq.html. Cited May 10, 2010

15. Osborn TM, Phillips G, Lemeshow S et al (2014) Sepsis Severity Score (SSS): an internationally derived scoring system from the Surviving Sepsis Campaign database. Crit Care Med 42(9):1969-1976

16. Royston P, Altman DG (1994) Regression using fractional polynomials of continuous covariates: parsimonious parametric modeling. Appl Stat 43:429-467 
17. Kaukonen KM, Bailey M, Suzuki S et al (2014) Mortality related to severe sepsis and septic Shock among critically ill patients in Australia and New Zealand, 2000-2012. JAMA 311(13):1308-1316

18. State of New York Public Health and Health Planning Council. Amendment to Sections 405.2 and 405.4 of Title 10 (Health) of the Official Compilation of Codes, Rules and Regulations of the State of New York http://www.health. ny.gov/facilities/public_health_and_ health_planning_council/meetings/ 2013-02-07/docs/13-01.pdf. Last accessed September 30, 2014
19. Miller RR, Dong L, Nelson NC et al (2013) Multicenter implementation of a severe sepsis and septic shock treatment bundle. Am J Respir Crit Care Med 188(1):77-82

20. Lefrant JY, Muller L, Raillard A et al (2010) Sepsi d'Oc Group in the AzuRea Group. Reduction of the severe sepsis or septic shock associated mortality by reinforcement of the resuscitation bundle: a multicenter study. Ann Fr Anesth Reanim 29(9):621-628

21. Wang Z, Xiong Y, Schorr C et al (2013) Impact of sepsis bundle strategy on outcomes of patients suffering from severe sepsis and septic shock in China. J Emerg Med 44(4):735-741
22. Van Zanten ARH, Brinkman S, Arbous $M$ et al (2014) Guideline bundles adherence and mortality in severe sepsis and septic shock. Crit Care Med 42(8):1890-1898

23. The ProCESS Investigators (2014) A randomized trial of protocol-based care for early septic shock. N Engl J Med 370(18):1683-1693 